whether he thinks that his parents have failed to show proper respect for him as being another human, and not a toy doll or a video puppy. It is whether, as a matter of fact, they have failed to show him that respect.

Notice, incidentally, the oddity approvingly quoted within the last quotation - the remark that the "family relationships that come from having both sons and daughters" are "unique". What am I, as a father only of daughters, to make of this? Are the authors trying to tell me that I am missing something by having no sons? Well, no doubt I am. But so is the father who does not, like me, enjoy the equally "unique" family relationships that come from having only daughters and no sons. So is the father who does not have my "unique" daughters missing something, just as I am missing something by not having his. Why should anyone go along with the implication that I am missing more than these other fathers - in some ill-defined sense of "more"? Even if it is true that I am missing something, or even missing "more" than they are - why is it impossible for me to think that in my daughters I have enough to be happy about, without looking for "more"?

The first issue regarding the ethics of sex selection, that of respect for humans, thus brings us to think about the reasons that typical members of Western societies or cultures are likely to have for wanting to engage in sex selection. One may form the impression that these reasons show a certain light-mindedness or frivolity - a lack of depth in our thinking about what makes people matter, which is a symptom of consumer capitalism's tendency to make a marketable commodity out of whatever it can, even gender. This impression of frivolous consumerism is not effectively dispelled by anything that the report says. Indeed the report seems to come down cautiously in favour of it.

It would perhaps be possible to argue that sex selection in itself entails inadequate respect for humans, and that that is why it should not be part of parents' reproductive freedom. However, the argument, which will not be attempted here, would not be straightforward. After all, pari passu it can be said that paying people less than some amount for their labour shows inadequate respect for humans. But not everyone who agrees with that claim believes that it follows that we should have a legal minimum wage.

However, suppose we turn to the second issue, that of the damaging consequences of sex selection. At this point, it seems to me, a straightforward argument for banning sex selection at least in societies like ours does come into view. And once again the argument is identified, but muffed, by the report (page 22):

"When women in India choose for a boy because 'they are reluctant to bring a female child into a society in which she will be abused and devalued, as they themselves have been', this is not a sexist reason [for sex selection]. . . . Even if the parental reasons are prompted [sic] by circumstances which can be described as institutional sexism ... it does not follow that what they do is sexist. Parents who opt for a boy because it is better for their child to be a boy in the prevailing situation do so on the basis of their responsibility for the well-being of their child. It is a fact that their choice can help to reinforce sexist structures and relationships but this only means that the situation is one of conflicting responsibilities in which it is inevitable that a moral price be paid."

As its woolly last sentence suggests, this sequence of thought is a muddled one. First point: why should a committee set up to make recommendations to the Dutch Government, on the law regarding sex selection in Holland, feel obliged to consider the sociological situation in India? It is, unfortunately, true that there are rampantly sexist societies around, in which producing a female child is a disaster for the mother: but what has that got to do with the Netherlands? The only appealing answer to this question is that some inhabitants of the Netherlands are from those sexist societies and accept their attitudes. But this answer just brings us to the second point - which is that unless one views society as some sort of moral vacuum, one is likely to think that it is a government's job to prevent blatant abuses of human rights within its own jurisdiction, not shrug its shoulders at them. This remains so even when those abuses are perpetrated by members of the society who, as immigrants and members of ethnic minorities, indisputably deserve a little bit of leeway and understanding. In a decent society we should say that if anyone, whatever their background, is coercing mothers to produce sons, and victimising them and their children if they do not comply, then they should be open to the punishment of law, where punishment is possible. Moreover, we should do what we can in advance, to prevent such abuses. But allowing sex selection is not just not preventing these abuses: it is positively encouraging them. Hence one plausible argument for not allowing sex selection in our society depends on the circumstance that there are large numbers of people in our society who would be likely to use it as an instrument for coercion and for the reinforcement of a whole framework of what our society is unavoidably committed to regarding as unjust social structures and attitudes. And this framework is one within which, incidentally, the report's attempt to distinguish the parents' own attitudes and actions from those dictated to them by "the prevailing situation in which they find themselves", seems to register a failure to understand that a crucial aspect of the problem is precisely that in the cases in question there is no such distinction to be drawn.

This report is an interesting document, and it is clearly and effectively written; but - as so often with government reports - the actual argument is wishy-washy and unconvincing.

TIMOTHY CHAPPELL School of Philosophical Studies, University of Manchester

\section{Treatment without consent. Law, Psychiatry and the Treatment of Mentally Disordered People since 1845}

P Fennell, London, Routledge, 1996, 356 pages, £50.

Avoiding anachronism and the passing of irrelevant moral judgment remains one of the unresolved problems of medico-legal historiography. According to some, applying current scientific or ethical standards (which in historical work are far more integrated than is usually allowed) to old forms of medical care is, at best, poor historical scholarship, and at worst a 
demonstration of jaundiced prejudice. To others, however, ethical standards must be considered as being sub specie eternitatis and hence medical procedures from all historical periods must be lambasted if thought not to have come up to scratch. In this conflict, unsurprisingly, the proverbial via media is not easy to define, inter alia, because it is difficult to know enough about the circumstances of past medical events to decide whether those involved took sufficient care of the ethical aspects of their behaviour. For example, recent historical work on ECT and psychosurgery shows that those involved in the early development and application of these treatments showed far more ethical preoccupation than hitherto has been thought to be the case, particularly by "historians" who have chosen to dub such procedures as criminal and unethical tout court.

A good example of this can be found in a feature article in The Times, ${ }^{1}$ where quotation marks and staccato narrative are meant to make the poor reader squirm: "he was taken to a windowless room and told to get into bed. He was given a stack of male erotica magazines and a supply of Guinness, his favourite drink. A short while later, three staff came into the room and gave him an injection. Soon after he vomited. He asked for a bowl but was told to be sick in bed". Were things as simple as that? Why should one accept this particular narrative as the more plausible or constructive one? Is the intention of the writer to understand the event so that something similar "does not happen again" (as the current cliché goes) or is he just a tout court man? It would seem that the latter is the case, for the author makes little effort to contextualise the episode in order to decide whether or not the treatment in question was in keeping with the scientific, social and ethical warrants valid during the 1970 s. Whether the procedure under the microscope is aversion therapy or psychosurgery, ECT, psychopharmacology, psychotherapy or "no treatment at all" (ie respecting the human right to remain ill) the bottom line will always be determined by the historian's agenda.

The book under review is unsuccessful in the solving of these problems. Indeed, the author - an academic lawyer - sometimes gives the impression that he is not aware of them at all. There is little doubt, however, that he has written a major analytic piece, bringing together the conceptual evolution of mental health legislation since approximately 1845 and issues concerning "consent" for a number of biological treatments in psychiatry. Sixteen closely argued chapters are complemented by useful tables of statutes, cases, and notes. Historiography is linear and "internalist", ie philosophical or socio-political accounts are kept to a minimum. As explanans the author seems to rely on the good old concept of Sitte ("custom" - fashionably translated nowadays as "social practice"), developed by the great Rudolph von Ihering in the wake of Darwinian theory. By skilfully using the cross-talk method of presentation, Fennell is able to show lateral interactions between changes in legal framework, legal decisions and psychiatric practices. The strength of this book is to be found in its firm and crystalline analysis of the concepts governing the attitude of legislators and lawyers towards psychiatry, and in its important conclusion that the therapeutic boundaries within which British psychiatrists operate have since the 19 th century been determined by the courts.

On the negative side, the book does not make any effort to compare British and continental ideas or to relate the conceptual status of "consent" in psychiatry with that of general medicine and surgery. This lack of contextualisation is at its worst when dealing with the role of psychiatry and the manner in which biological treatments were developed and applied. This results from both poor choice of secondary historical sources (for example Valenstein on psychosurgery may be a wonderful pamphlet in defence of human rights but is lousy history) and limited primary historical research. This is a pity, for whenever the author has undertaken the latter the results are of the highest quality as shown, for example, by chapter 5 . Had Fennell brought himself to do likewise with the rest of the chapters we would now be reviewing a great historical work, a book free from claims such as the one that 19th century "psychiatrists" were entrepreneurs, avid for "professional domination" of the mental disorder market, a claim which, as should be obvious to all, is but a Deus ex machina that gets in the way of proper historical research into the professionalisation of psychiatry.

This book offers little in the way of solutions. There is, of course, obligation for the author to do so, bat critical works like his impose a moral duty to suggest at least one, particalarly when we are told that "users awd survivors of psychiatry . . . argue the right to be treated without drugs". If that is the case, then the author should tell to what other treat ments he refers, and proceed $0 \% 0$ analyse them from the point of view- $f$ consent, with the same keenness with which he analyses the biological tregtments. It may be that, as Europeam legislation looms larger, Fennell feejs that what it has to offer is go®d enough and that Britain ought to pt ball. However, solutions by defaubt are not always the best. We still nett a coherent theoretical position to deal with what American and Continengal psychiatrists are beginning to face, to wit, being taken to court for $n$ forcing treatment upon "users" क् f psychiatry who at the time were incapable of giving consent. Whatefgr the new theoretical position, it will have to start from the principle thati் the serious business of helpigg patients with "mental illness", historians, lawyers, medics and the rest society must work together.

In conclusion, this book delivę only part of what it promises but what it does is good enough. It is excelle on the analysis of mental health legistation, adequate on the analysis of vicissitudes of the complex notion - of consent, and bad on the history of $\overline{\mathrm{m}} \mathrm{e}$ biological treatments in psychiatry. As discussed above, this is to a large extent understandable, and should not put gff prospective readers; indeed, it is only work around trying to link these three fascinating themes.

\section{Reference}

1 Laurence J. How gay men were "cured". The Times 1996 Jul $20:$ 16 (col 1).

G E BERRIE్s

Chair, Local Research Ethxics Committefe,

Cambridge District University of Cambridge

Final Acts of Love, Families, Friends and Assisted Dying

Stephen Jamison, New York, G P Putnam and Sons, 1995, 278 pages, US \$23.95. 